University of Nebraska - Lincoln

DigitalCommons@University of Nebraska - Lincoln

Faculty Publications from the Harold W. Manter Laboratory of Parasitology

\title{
Synlophe Structure in Pseudomarshallagia elongata (Nematoda: Trichostrongyloidea) Abomasal Parasites among Ethiopian Ungulates, with Consideration of Other Morphological Attributes and Differentiation within the Ostertagiinae
}

\author{
Eric P. Hoberg \\ United States Department of Agriculture, Agricultural Research Service, ehoberg@ggpl.arsusda.gov \\ Bersissa Kumsa \\ Addis Ababa University \\ Patricia A. Pillit \\ United States Department of Agriculture, Agricultural Research Service \\ Arthur Abrams \\ United States Department of Agriculture, Agricultural Research Service
}

Follow this and additional works at: https://digitalcommons.unl.edu/parasitologyfacpubs

Part of the Parasitology Commons

Hoberg, Eric P.; Kumsa, Bersissa; Pillit, Patricia A.; and Abrams, Arthur, "Synlophe Structure in Pseudomarshallagia elongata (Nematoda: Trichostrongyloidea) Abomasal Parasites among Ethiopian Ungulates, with Consideration of Other Morphological Attributes and Differentiation within the Ostertagiinae" (2010). Faculty Publications from the Harold W. Manter Laboratory of Parasitology. 609. https://digitalcommons.unl.edu/parasitologyfacpubs/609

This Article is brought to you for free and open access by the Parasitology, Harold W. Manter Laboratory of at DigitalCommons@University of Nebraska - Lincoln. It has been accepted for inclusion in Faculty Publications from the Harold W. Manter Laboratory of Parasitology by an authorized administrator of DigitalCommons@University of Nebraska - Lincoln. 


\title{
SYNLOPHE STRUCTURE IN PSEUDOMARSHALLAGIA ELONGATA (NEMATODA: TRICHOSTRONGYLOIDEA), ABOMASAL PARASITES AMONG ETHIOPIAN UNGULATES, WITH CONSIDERATION OF OTHER MORPHOLOGICAL ATTRIBUTES AND DIFFERENTIATION WITHIN THE OSTERTAGIINAE
}

\author{
Eric P. Hoberg, Bersissa Kumsa*, Patricia A. Pilitt, and Arthur Abrams \\ U.S. National Parasite Collection and Animal Parasitic Disease Laboratory, U.S. Department of Agriculture, Agricultural Research Service, \\ BARC East, BIdg 1180, 10300 Baltimore Avenue, Beltsville, Maryland 20705. e-mail: eric.hoberg@ars.usda.gov
}

\begin{abstract}
The independence of Pseudomarshallagia and its placement among the medium stomach worms of ungulates, Ostertagiinae, is confirmed based on comparative morphological studies of the synlophe and genital attributes among male and female specimens. An emended description of Pseudomarshallagia elongata is presented based on a series of specimens in sheep from northern Ethiopia. Pseudomarshallagia elongata is retained among the 15 genera of the Ostertagiinae based on presence of a prominent esophageal-intestinal valve, paired "0" papillae, a modified accessory bursal membrane containing the paired "7" papillae, and configuration of the copulatory bursa. The structure of the synlophe in males and females is also typical and within the range of variation demonstrated for Type II and Type A cervical patterns among other ostertagiines. We emphasize the importance of continued survey and inventory of parasite faunas to establish the limits of diversity on local, regional, and global scales. Consequently we strongly encourage routine deposition of voucher specimens from all survey activities designed to explore faunal diversity. Although this is particularly important in regions that remain poorly known, such as Africa, the principle certainly applies more broadly.
\end{abstract}

Pseudomarshallagia elongata (Roetti, 1941) was established for medium stomach worms (Ostertagiinae) found in sheep (Ovis aries (Linnaeus)) and goats (Capra hircus (Linnaeus)) from Jimma and Addis Ababa, Ethiopia (Roetti, 1941; Graber and Delavenay, 1978). These nematodes and related haemonchines are a major component of the parasite fauna in small ruminants (sheep and goats) across this region, and, collectively, disease, mortality, and annual production losses estimated near US\$400 million represent a major challenge to socioeconomic development and food security (Kumsa and Wossene, 2006; Biffa et al., 2007). Pseuodmarshallagia elongata appears endemic or geographically limited to Ethiopia, where it is a ubiquitous nematode parasite of sheep and goats in the highland areas (Biffa et al., 2007). A history of surveys of free-ranging and domestic ruminants across sub-Saharan Africa has not revealed the occurrence of $P$. elongata outside the Ethiopian region (e.g., Hoberg, Abrams, and Ezenwa, 2008). Faunal inventory for stomach worms in free-ranging ungulates of Ethiopia may serve to define the limits of host associations for this, and related, ostertagiines.

The present study contributes to a more detailed understanding of nematode diversity among ungulate hosts from Ethiopia and more broadly across sub-Saharan Africa (Hoberg, Abrams, and Ezenwa, 2008). Knowledge of parasite diversity, including host associations and geographic distribution, is a cornerstone in development of effective strategies for control of parasitism. The continued global translocation and introduction of exotic parasites further establishes a rationale for the development of effective baselines for identification, which are necessary to track dissemination of pathogens and emergence of disease in space and time (Hoberg, 1997; Smith et al., 2009).

Originally recognized as a subgenus of Ostertagia Ransom, 1907, Pseudomarshallagia (Roetti, 1941) was the subject of a redescription by Graber and Delavenay (1978), which also resulted in elevation to full generic rank. Gibbons (1981) and

Received 11 June 2009; revised 16 October 2009; accepted 28 October 2009.

* Department of Parasitology and Pathology, Faculty of Veterinary Medicine, Addis Ababa University, P.O. Box 34, Debre Ziet, Ethiopia. DOI: 10.1645/GE-2204.1
Gibbons and Khalil (1982) clarified some morphological details for this species and justified placement among the Ostertagiinae as a discrete genus. Durette-Desset (1983) included Pseudomarshallagia among the synonyms of Longistrongylus Le Roux, 1931. Structural characters typical of $P$. elongata indicate that it is independent from Longistrongylus and other ostertagiine nematodes characterized by a 2-1-2 bursal formula (Gibbons, 1981; Hoberg and Abrams, 2008; Hoberg, Abrams, and Ezenwa, 2008; Hoberg et al., 2009a, 2009b).

Few specimens representing $P$. elongata have been archived in museum collections, and the location of the type specimens remains undetermined (Roetti, 1941). Although the species is considered characteristic among sheep and goats in Ethiopia, specimens resulting from parasitological surveys have seldom been deposited among museums either in Africa or globally (Tembely et al., 1997; Biffa et al., 2007; reviewed in Hoberg, Abrams, and Ezenwa, 2008). In part, this paucity of material has contributed to confusion in taxonomy resulting from a poor or incomplete definition of various structural characters. For example, the synlophe, or system of surface cuticular ridges, which is among the most important diagnostic characters among the ostertagiines, has never been adequately characterized (Durette-Desset, 1983; Lichtenfels et al., 1988; Hoberg et al., 2009b).

Recent collections of new specimens in domestic sheep from the northern highlands of Ethiopia now provide the opportunity to describe the structure of the synlophe in males and females and to explore details of the basal esophagus genital cone and other attributes that have not previously been assessed. In the current study, we complete an emended description of $P$. elongata and present aspects of comparative morphology relevant to establishing a context for this species among the ostertagiines and as a component of the nematode fauna of African ungulates.

\section{MATERIALS AND METHODS}

\section{Specimens examined}

Specimens representing $P$. elongata from Ethiopia are as follows: (1) Voucher specimens in $O$. aries, represented by 4 permanent slides including male with detached bursa, dissected spicules, and 2 slides with 
THE JOURNAL OF PARASITOLOGY, VOL. 96, NO. 2, APRIL 2010
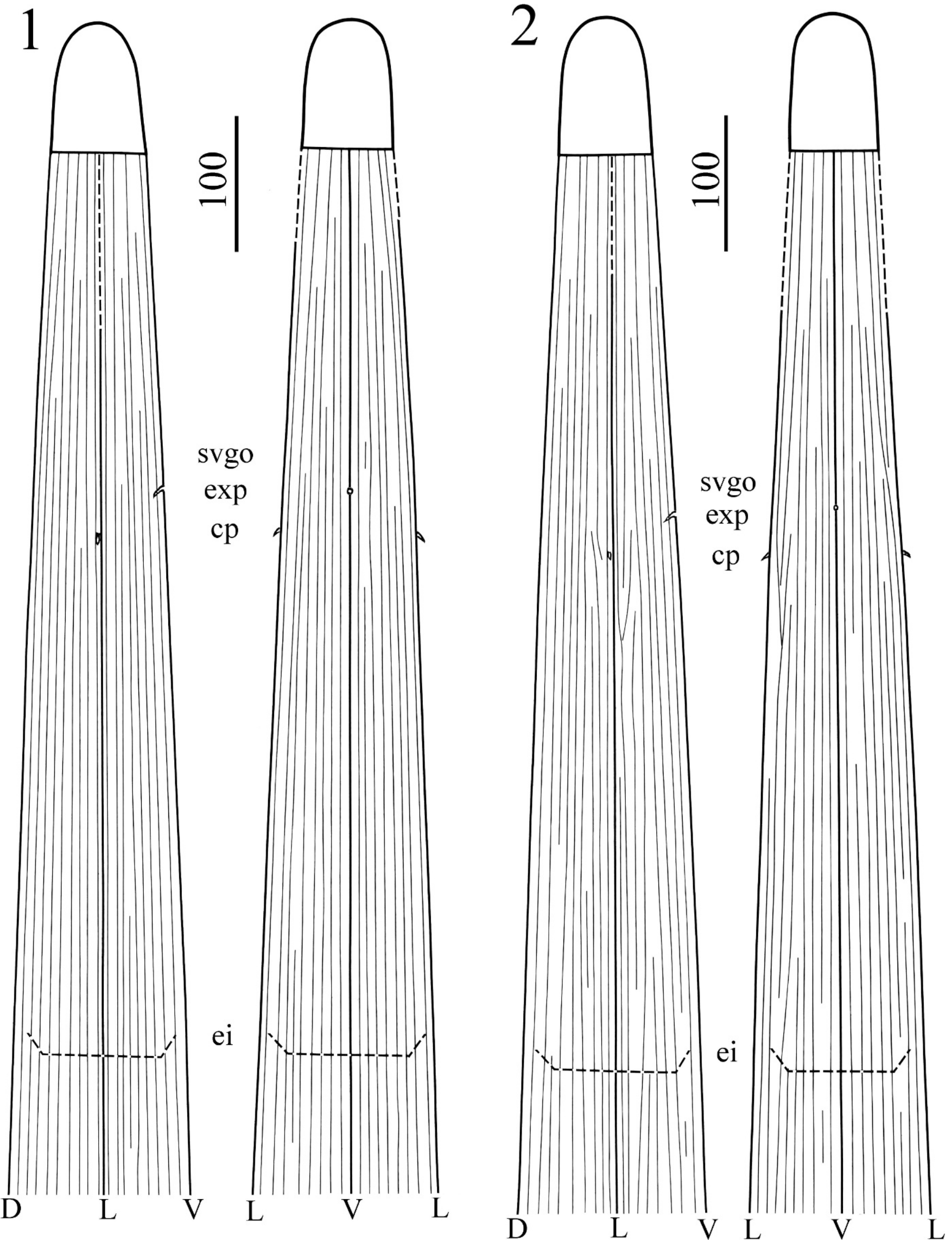
transverse sections deposited by $\mathrm{M}$. Graber under Commonwealth Institute of Helminthology (CIH) no. 3358, now held by the Royal Veterinary College, London. These specimens appear to be part of the material from the redescription by Graber and Delavenay (1978) and were also examined by Gibbons (1981) and Gibbons and Khalil (1982). (2) Voucher specimens include 20 males and 20+ females (and fragments) in $O$. aries, collected from the abomasa of 10 sheep (Menez breed) at Debre Brehan, Ethiopia, ca. $09^{\circ} 36^{\prime} \mathrm{N}, 039^{\circ} 38^{\prime} \mathrm{E}$, by B. Kumsa on 11 October 2008, now held in the U.S. National Parasite Collection, USDA, Beltsville, Maryland, under USNPC 101404. Taxonomy for ruminant species is consistent with Wilson and Reeder (2005).

\section{Microscopy}

Nematodes, including 15 males and 15 females, under USNPC 101404 were prepared as temporary whole mounts cleared in phenol-alcohol ( 80 parts melted phenol crystals and 20 parts absolute ethanol) and examined with interference contrast microscopy; meristic data were derived from the study of 10 complete males and 10 complete females. The synlophe was examined in whole mounts with particular attention given to the pattern of ridge systems in the cervical zone and their extent posteriad in males and females consistent with prior studies among the ostertagiines (Lichtenfels et al., 1988; Hoberg et al., 1999, 2009b). Transverse sections from 2 males and 2 females were hand cut with a cataract knife and mounted in glycerin jelly. Sections were used to examine the orientation and gradients of ridges (Durette-Desset, 1983) and to count the number of ridges at the esophageal-intestinal junction (EIJ), first quarter, midbody, end of the third quarter, and in the fourth quarter of total body length as determined from the anterior. In males, characters of the bursa and genital cone are consistent with Durette-Desset (1983) and Gibbons and Khalil (1982). In females, description of the ovejectors is consistent with Lichtenfels et al. (2003). All measurements in the emended description are presented in micrometers, sample sizes are denoted as $(\mathrm{n}=)$, and the range is followed by the mean $\pm 1 \mathrm{SD}$.

\section{EMENDED DESCRIPTION}

\section{Pseudomarshallagia elongata}

(Figs. 1-28)

General description: Trichostrongyloidea, uncoiled, straight, maximum diameter attained near third quarter of body length from anterior, 125-128 in males and 187 at vulva and in posterior quarter in females. Cephalic vesicle present as bipartite expansion; posterior portion strongly annulated but cryptic (Figs. 7, 8). Cuticle with well-developed synlophe (Figs. 1-6), lacking gradient, with perpendicular orientation; maximum number of ridges, 39, near the level of EIJ. Nerve ring (NR) prominent, anterior to orifices of subventral glands (SVGO) in anterior third of cervical region. Cervical papillae (CP) miniscule, thorn-like, situated posterior to level of excretory pore (EXP) (Figs. 10, 11). Position of CP and EXP usually distal to SVGO near mid-length of esophagus (Figs. 1, 2, 7). Cuticular ornamentation at level of EXP lacking. Esophagus well developed, maximum diameter attained at cylindrical esophageal-intestinal valve (EIV) (Figs. 7, 9). Males and females monomorphic.

Synlophe structure: Synlophe bilaterally symmetrical; ridges extending from base of cephalic expansion to near caudal extremity in males and females (Figs. 1,2). Ridges acutely pointed, with perpendicular orientation and absence of gradient as viewed in transverse section. Laterally in cervical zone with Type II pattern and 3-5 ridge system; lateral-most ridge bordering $\mathrm{CP}$, and 1-2 parallel ridges bordering miniscule cervical papilla in each field (Figs. 1, 2); in some specimens, 1 pair of isolated ridges bordering lateral ridge initiate near base of cephalic expansion, terminating anterior to cervical papillae in left and right fields. Continuous sublateral ridges present. Ridges added through cervical zone in sublateral fields bordering 3-5 ridge lateral-most system. Ventrally, Type A pattern where 2 continuous ridges parallel single ventralmost ridge bisecting excretory pore. Synlophe extends posteriad to near prebursal papillae in males and posterior to anus in females. Maximum number of ridges, 37-38 and 39 in males and females, respectively, attained near level of esophageal-intestinal junction. In male specimens, 30-33 ridges in first quarter, 32-34 at midbody, $32-34$ at end of third quarter; in females 36 in first quarter, 34 at midbody, 35 at level of vulva (Figs. 3-6). In males, ridges terminate anterior to prebursal papillae first in ventral and later in dorsal field; synlophe retained in the lateral fields. In females, series of ridges hypertrophied ventrally at level of vulva.

Male characters: Medium trichostrongyloid nematodes with prominent copulatory bursa (Figs. 12-15). Total length $(\mathrm{n}=10)$ 9,424-12,210 (11,087 \pm 840$)$; maximum width $(\mathrm{n}=10)$ 120-145 attained near end of third quarter of body length measured from anterior. Esophagus $(\mathrm{n}=10)$ 550-790 (707 \pm 63$)$ long; 5.4-7.8\% of total body length. Valve at EIJ cylindrical, longer than wide $(\mathrm{n}=$ 10) $80-115(101 \pm 11.7)$ in length by $(n=10) 47-52(50 \pm 1.7)$ in maximum width. Cephalic vesicle $(\mathrm{n}=8) 65-89(79 \pm 9.4)$. NR $(\mathrm{n}$ = 10) 217-290 (251 \pm 25.8$),$ SVGO $(\mathrm{n}=10)$ 265-325 (293 \pm 21.5$)$, $\operatorname{EXP}(\mathrm{n}=10) 260-360(310 \pm 35)$, and CP $(\mathrm{n}=10) 262-410(334 \pm$ 45) from cephalic extremity; in 9 specimens position of EXP at 36$47 \%$ and $\mathrm{CP}$ at $38-48 \%$ of esophageal length from anterior (Fig. 7); in 1 specimen 60 and $65 \%$. Copulatory bursa symmetrical, of type 2-1-2, $(\mathrm{n}=10) 212-275(240 \pm 22)$ in length from prominent prebursal papillae (Fig. 12). Rays $2 / 3$ curved, divergent along length, strongly converging at tips, extending to margin of bursal membrane (Fig. 13). Rays 3 greater in diameter relative to Rays 2; thickness of Rays 3, with narrow distal tip, less than that of Rays 4. Rays 4 relatively straight, extending to bursal margin, exceeding Rays $2 / 3$ and 5/6 in length. Rays 5/6 narrow, divergent throughout length; discrete fields of diffuse bosses on bursa limited distally around Rays 5/6. Rays 8, narrow, slight, curved medially, extending to margin of bursa (Fig. 14). Dorsal ray bulbous, broadly inflated proximally, at base $(n=6) 29-34(32 \pm 2.1)$ wide (Figs. 15, 19); strongly tapers distally, lyre-shaped, relatively short $(\mathrm{n}=10)$ 35-50 $(41 \pm 4.8)$ in length with slight distal bifurcation containing papillae $9 / 10$. Dorsal lobe reduced, disposed ventrally to Rays 8, laterally inflated distally $(n=6) 31-36(34 \pm 2.1)$ in width, substantially exceeds width of dorsal ray $(n=6) 13-16(14 \pm 1.2)$ at level of bifurcation (Figs. 14, 15, 19, 23). Genital cone with

Figures 1-2. Pseudomarshalagia elongata showing variation in pattern for the synlophe in lateral and ventral fields in the cervical zone anterior to the base of the esophagus in representative male and female specimens in Ovis aries, USNPC 101404; scales in micrometers. (1) Male specimen with parallel Type II lateral and Type A ventral systems. Note cervical papillae (cp) adjacent to lateralmost ridge, the 3 (5) ridge lateral system, and excretory pore (exp) on the ventralmost ridge and position of the esophageal-intestinal junction (ei); orifices of the subventral esophageal glands (svgo) are situated anterior to the exp and cp; orientation is indicated by $\mathrm{L}=$ lateral, $\mathrm{D}=$ dorsal, and $\mathrm{V}=$ ventral. Dashed lines denote variation in placement for origins of ridges in the anterior of the cervical region. (2) Female specimen with Type II lateral and Type A ventral synlophe, showing variation in pattern of cervical synlophe in the subventral and subdorsal fields adjacent to the lateral systems. 


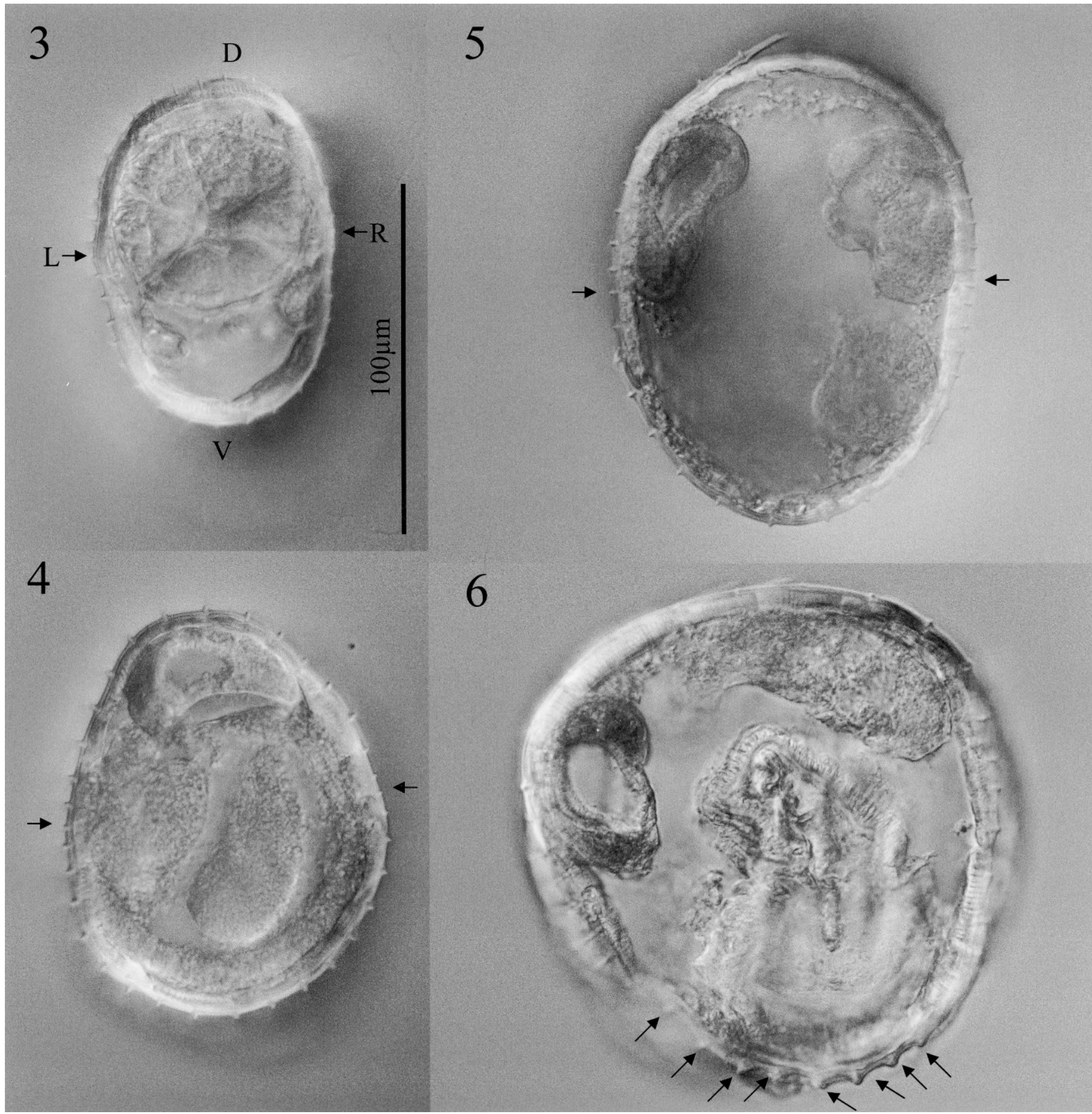

FiguREs 3-6. Pseudomarshallagia elongata showing structure of synlophe as seen in photomicrographs of transverse sections of a female at different levels of the body from the anterior; scale and orientation are the same for all figures, USNPC 101404. (3) Synlophe near level of esophageal-intestinal junction, showing 38 ridges; $\mathrm{D}=$ dorsal, $\mathrm{V}=$ ventral, $\mathrm{L}=$ left lateral, and $\mathrm{R}=$ right lateral. (4) Synlophe at midbody showing 34 ridges, arrows indicate lateral fields. (5) Synlophe at end of third quarter showing 35 ridges. (6) Synlophe at level through vulva showing 35 ridges; note series of 8 hypertrophied ridges across ventral field (arrows).

rounded, bilobed ventral genital inflation situated antero-ventral to cloaca with lobes bordering cryptic, paired "0" papillae with rounded tips (Figs. 16, 23). Cloaca with telamon and cuticularized support structures surrounding orifice. Accessory bursal membrane inconspicuous in dorso-ventral view; broadened, shieldlike extending from dorsal aspect of genital cone and cloaca, with prominent paired papillae "7" evident on distal margin (Figs. 17, $18,23)$. Spicules robust, equal in length $(\mathrm{n}=10) 185-220(200 \pm$ 12.9), with bifurcation of prominent dorsal process, as extension of ala at $16-25 \%$ of total length from anterior. In lateral view, spicules straight, strongly cuticularized (Fig. 20). Dorsal process simple, massive, with prominent triangular barb in dorso-ventral view 


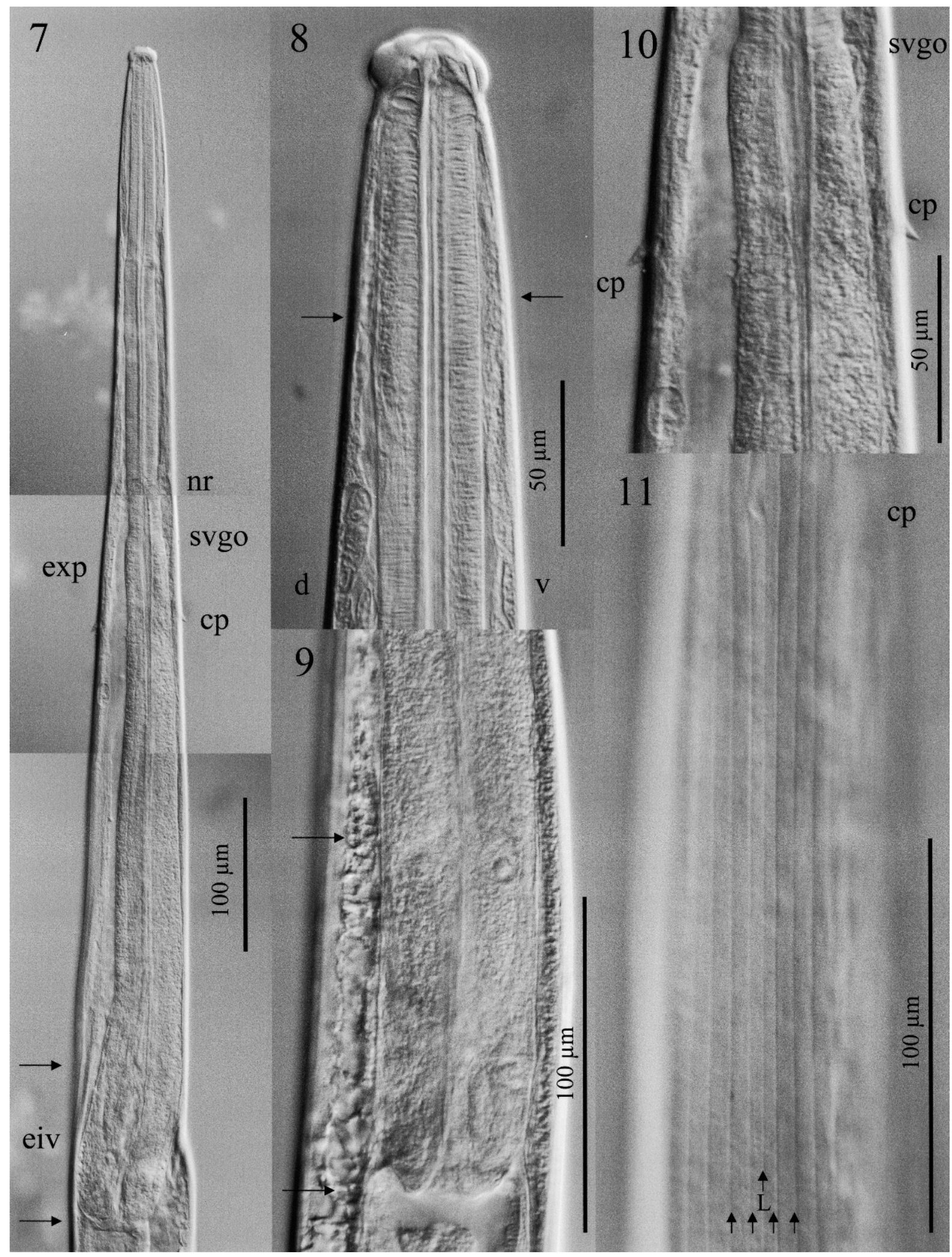

FIGURES 7-11. Pseudomarshallagia elongata showing cephalic structures in a representative male specimen, USNPC 101404, based on photomicrographs. (7) Composite reconstruction of the cervical zone showing the structure of the esophagus and positions of the nerve ring (nr) orifices of the subventral glands (svgo), excretory pore (exp), and miniscule cervical papillae (cp) in ventral view. Note relatively small esophagealintestinal valve (eiv) between arrows. (8) Cephalic expansion in right lateral view showing bipartite structure with well-developed anterior inflation and indistinct annulated region (termination indicated by arrows; $\mathrm{d}=$ dorsal, and $\mathrm{v}=$ ventral. (9) Esophageal-intestinal valve, showing narrow cylindrical form (between arrows). (10) Cervical papillae (cp) showing typical thorn-like structure; note position of the orifices of the subventral glands (svgo). (11) Cervical synlophe in lateral view, showing 5 ridge lateral-most system (arrows) and lateral ridge (L); note position of cervical papilla (cp). 


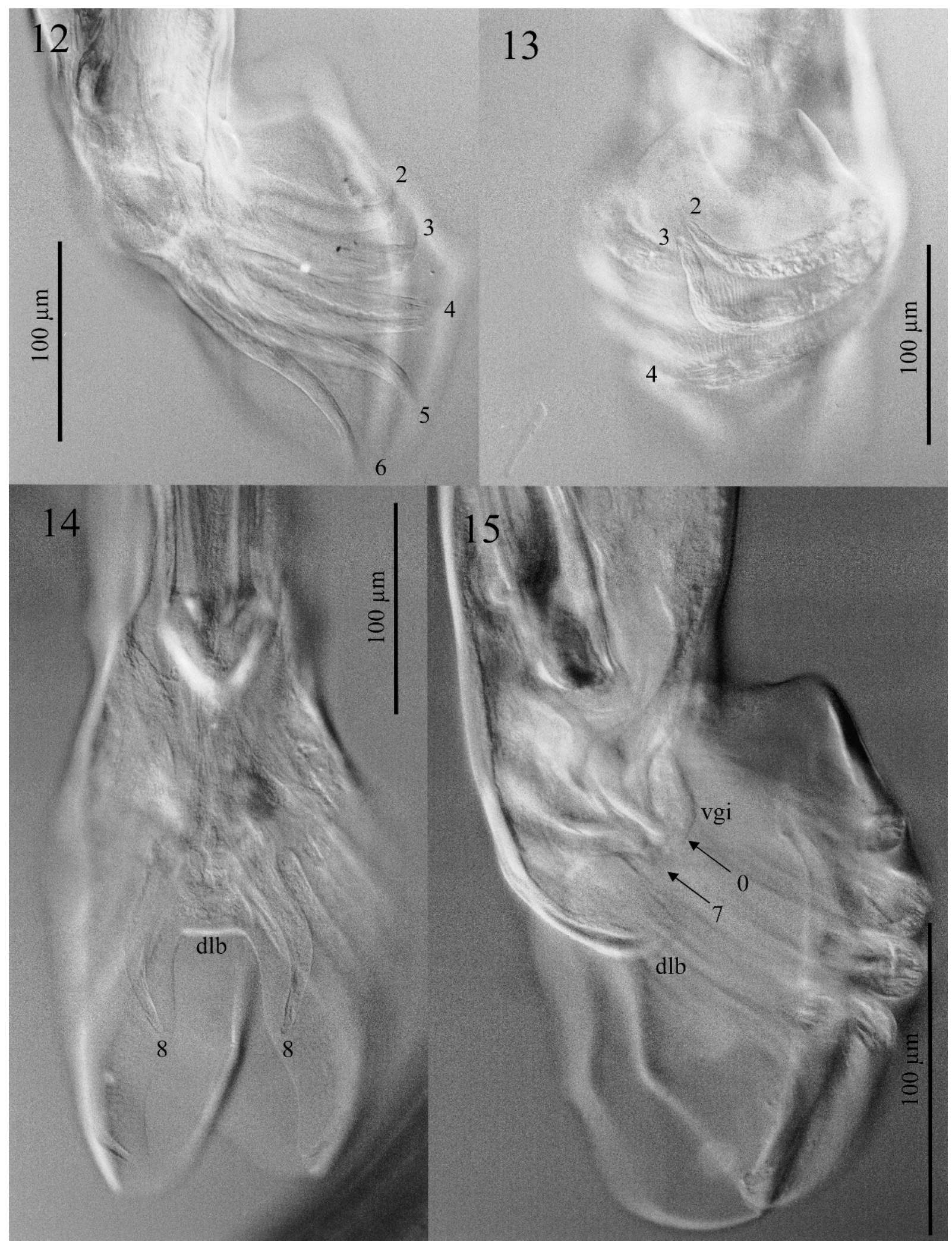

FIGURES 12-15. Pseudomarshallagia elongata showing structure of copulatory bursa in voucher specimens, USNPC 101404, based on photomicrographs. (12) Copulatory bursa in right lateral view showing relative positions of lateral rays in a 2-1-2 pattern. Rays are numbered (2-6) according to Durette-Desset (1983). (13) Copulatory bursa in ventral view showing relative position for Rays 2, 3, and 4. (14) Copulatory bursa in dorsal view showing position of Rays 8 and reduced and laterally inflated dorsal lobe (dlb). (15) Copulatory bursa in right lateral view showing structure of genital cone and relative position for the dorsal lobe (dlb), accessory bursal membrane and "7" papillae, "0" papillae on antero-ventral margin of cloaca, and ventral genital inflation (vgi). 


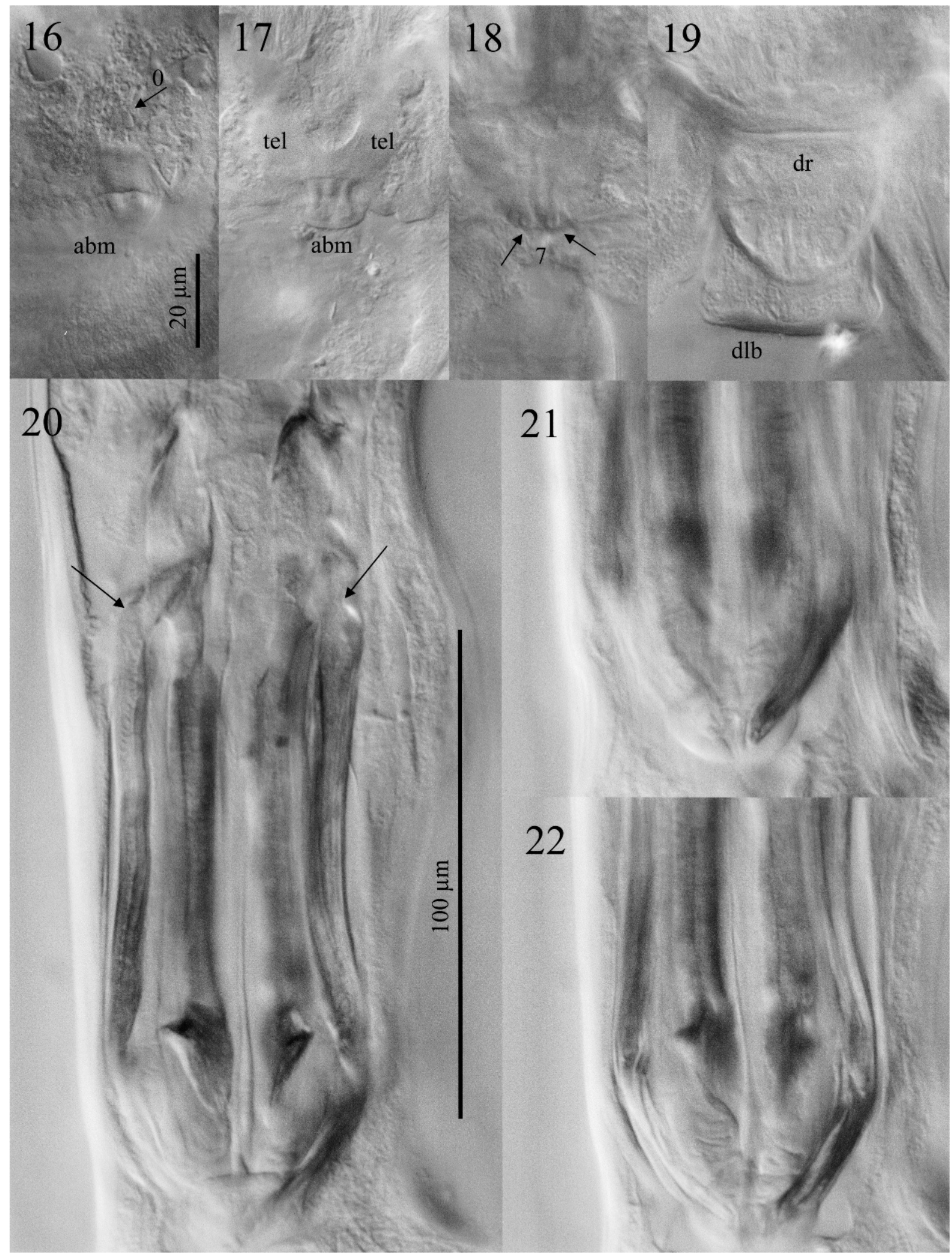

FIGURES 16-22. Pseudomarshallagia elongata showing structure of genital cone and dorsal ray and spicules in voucher specimens from USNPC 101404 based on photomicrographs. (16-19) Genital cone in ventral view, sequentially from ventral to dorsal, showing: (16) Paired " 0 " papillae (0) and position of the accessory bursal membrane (abm). (17) Accessory bursal membrane (abm) containing paired " 7 " papillae extending posteriad from genital cone ventral to cloaca; note relationship to plate-like telamon (tel) surrounding orifice of cloaca. (18) Shield-like structure of the accessory bursal membrane and position of "7" papillae (7). (19) Dorsal lobe (dlb) and proximal inflation of the dorsal ray (dr). (20) Spicules, left and right in dorsal view, showing position of bifurcation (arrows) and structure of triangular dorsal process and medially curved main shaft. (21) Spicule tips showing curved main shaft and prominent hyaline foot. (22) Spicule tips showing complex structure of membranes distally. 


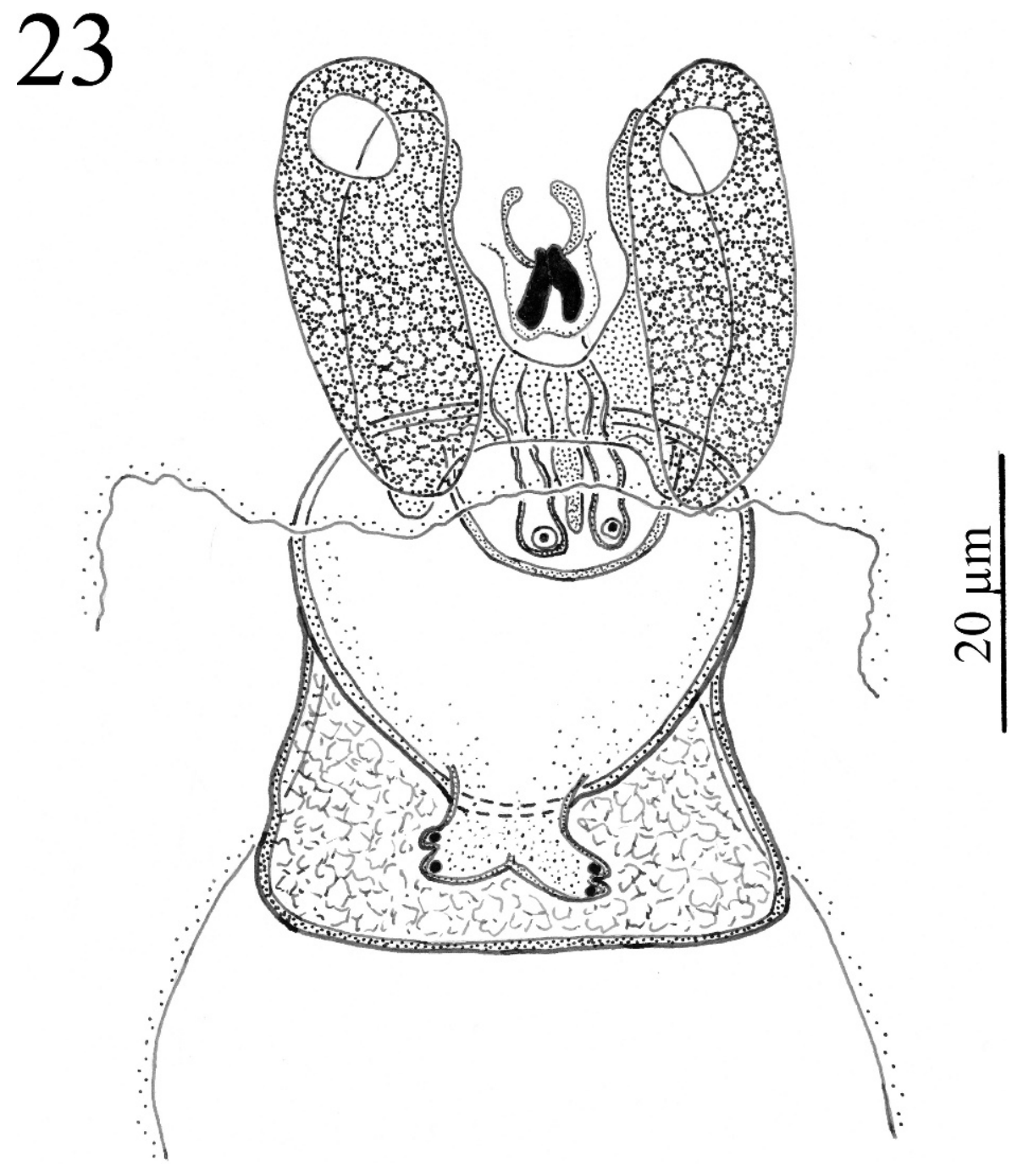

Figure 23. Pseudomarshallagia elongata showing structure of genital cone in male specimen in ventral view, USNPC 101404, based on line drawing; scale in $\mu \mathrm{m}$. Note structure and position of bilobed ventral genital inflation, paired " 0 " papillae, reduced accessory bursal membrane containing paired 7 papillae, inflated dorsal ray, and reduced dorsal lobe.
(Figs. 20, 22); ventral process absent. Main shaft tapering to blunt point turning mediad, with strongly developed and curved hyaline foot (Fig. 21). Complex membranes present on distal aspect of spicules (Fig. 22). Gubernaculum lacking.

Female characters: Trichostrongyloids of medium dimensions, lacking prominent cuticular ornamentation other than synlophe. Total length $(\mathrm{n}=10)$ 11,879-16,067(14,539 $\pm 1,391)$; maximum width $(\mathrm{n}=10)$ 140-187 attained near level of vulva into posterior quarter of body length measured from anterior; ratio of total body length:maximum width 1:71-104. Cephalic vesicle $(\mathrm{n}=8)$ $78-89$ (83 \pm 3.3$)$. Esophagus $(n=10) 686-769$ (728 \pm 25$)$ long; 4.5-6.3\% (5.0 \pm 0.5$)$ of total body length. Valve at EIJ, cylindrical, longer than wide $(n=10) 102-112(108 \pm 3.7)$ long, $(\mathrm{n}=10) 36-58(53 \pm 6.6)$ in maximum width. NR $(\mathrm{n}=10) 232$ 276 (260 \pm 13.7), SVGO (n = 10) 275-317 (298 \pm 12.4$),$ EXP (n = 10) 291-343 (312 \pm 17.9), and CP $(\mathrm{n}=10)$ 325-377 (347 \pm 19.5) from cephalic extremity; position of EXP at $41-46 \%$ and CP at $45-50 \%$ of esophageal length from anterior. Ovaries didelphic, amphidelphic, relatively straight. Vulva opens as ventral transverse slit at $(n=10) 9,949-13,216$ or $80-84 \%(82 \pm 1.2)$ of body length from anterior (Fig. 25); cuticular inflations and fans absent; synlophe ridges may be hypertrophied ventrally at level of vulva or in dorsal fields (Figs. 6, 26). Perivulvar pores not seen. Total ovejector length $(\mathrm{n}=8) 736-956(827 \pm 75.5)$ (Fig. 24). Anterior infundibulum $(\mathrm{n}=11)$ 174-200 (188 \pm 7.8$)$, bulb-like sphincter $\mathrm{s} 1(\mathrm{n}=8) 36-47(42 \pm 4.2)$, elongate sphincter $\mathrm{s} 2(\mathrm{n}=$ 8) 80-132 (100 \pm 17.8$)$, vestibulum $(n=8) 48-143(98 \pm 34.5)$ in length. Posterior infundibulum $(\mathrm{n}=8)$ 127-213 $(174 \pm 24.3)$, sphincter s1 $(n=8) 34-55(43 \pm 6.5)$, sphincter s2 $(n=8) 68-117$ $(91 \pm 15.4)$, vestibulum $(n=8) 40-112(75 \pm 25.5)$ in length. Eggs not seen. Tail conical $(\mathrm{n}=10)$ 104-168 (140 \pm 20.6$)$, bluntly rounded at caudal extremity, with weak annulations present distal to synlophe termination (Figs. 27, 28).

\section{DISCUSSION}

\section{Position within Ostertagiinae}

Pseudomarshallagia elongata is retained among the 15 genera of the Ostertagiinae based on the presence of a prominent EIV, paired " 0 " papillae, a modified accessory bursal membrane containing the paired " 7 " papillae, and configuration of the copulatory bursa (Figs. 9, 12-16, 17, 27) (Hoberg, Abrams, and Ezenwa, 2008). The structure of the synlophe in males and 


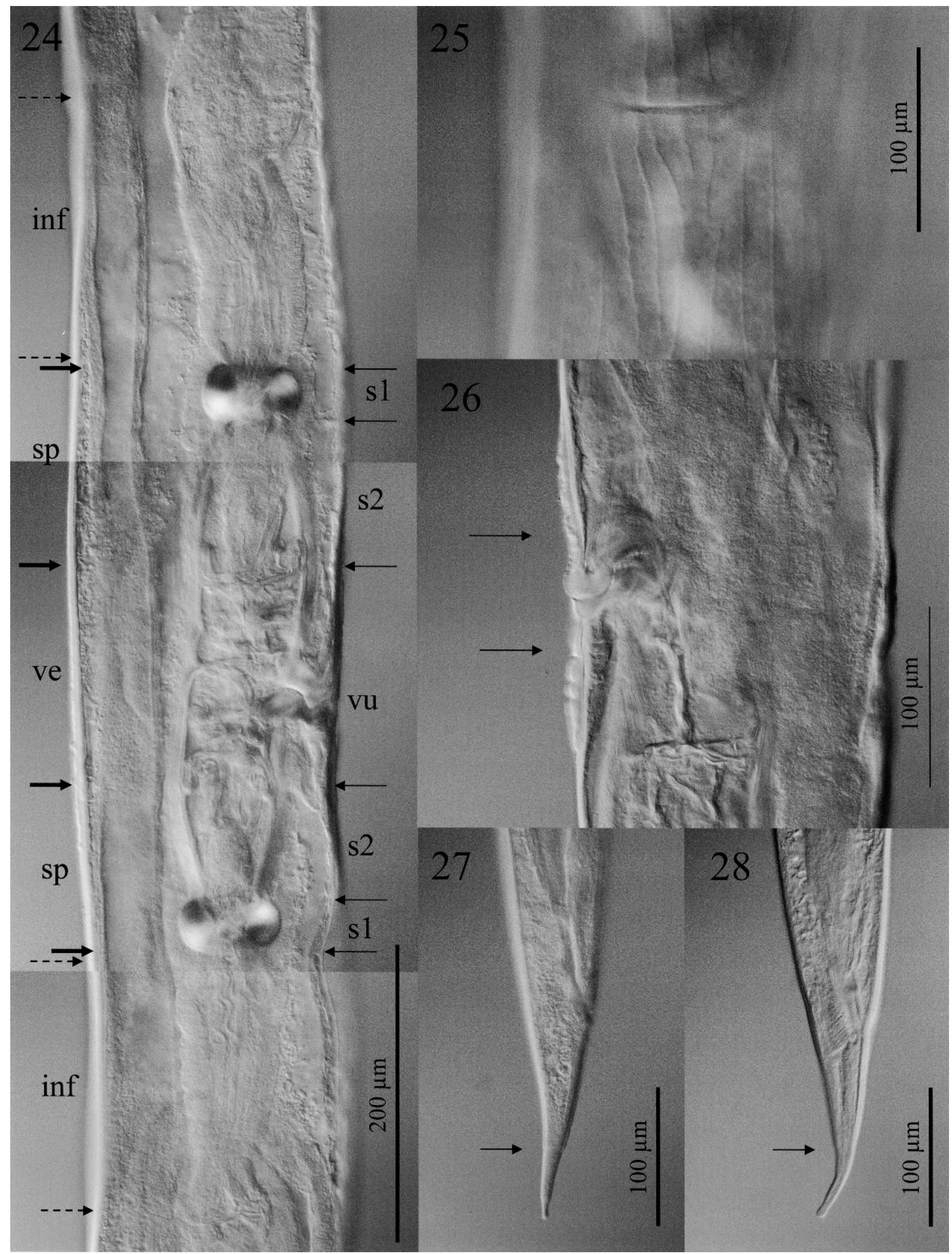

FIGURES 24-28. Pseudomarshallagia elongata showing diagnostic characters for female specimens, USNPC 101404, based on photomicrographs. (24) Ovejectors, composite image from single specimen, right lateral view, showing form and relative dimensions of the infundibula (inf between dotted arrows), sphincters (sp) including the bulb-like sphincter-1 (s1) and elongate sphincter-2 (s2), vestibule (ve), and transverse vulva (vu) lacking ornamentation. (25) Transverse vulva in ventral view showing distribution of ridges. (26) Vulva in left lateral view showing hypertrophied ridge (arrows). $(\mathbf{2 7}, \mathbf{2 8})$ Tail in right lateral view, showing conical structure and level of termination of the synlophe (arrow) posterior to anus. 
females is also typical and within the range of variation demonstrated for Type II and Type A cervical patterns among other ostertagiines (Figs. 1, 2) (Lichtenfels et al., 1988; Hoberg et al., 2009b). Similar to many of the ostertagiines, polymorphism among males of $P$. elongata has not been demonstrated (Dróżdż, 1995). Specimens of $P$. elongata contrast in the apparently unique structure of the spicules (Figs. 20-22) that lack both tripartite tips distally and the foramen-like ostertagiine window at the point of trifurcation for the dorsal and ventral branches from the main shaft that characterizes most genera and species in the subfamily (Gibbons and Khalil, 1982; Hoberg, Abrams, and Ezenwa, 2008).

Although the generic independence of Pseudomarshallagia is unequivocal (Graber and Delavenay, 1978; Gibbons, 1981; Gibbons and Khalil, 1982), P. elongata has often been designated as a subgenus of Longistrongylus (Tembely et al., 1997; Biffa et al., 2007). It is clear, however, that morphologically nematodes referred to these respective genera are distinct. Collectively, the 8 species of Longistrongylus are characterized by narrow filamentous spicules, a reduced dorsal lobe and ray that are disposed dorsally to Rays 8, filamentous, arcuate " 0 " papillae that terminate in bulbous expansions, a reduced and highly modified accessory bursal membrane in males, and irregular cuticular inflations at the level of the vulva in females (Gibbons, 1977; Gibbons and Khalil, 1982; Hoberg et al., 1993a; Hoberg, Abrams, and Ezenwa, 2008). Additionally for most species of Longistrongylus the maximum number of ridges comprising the synlophe among conspecifics is greater in males than in females (Hoberg et al., 2009b).

Specimens of $P$. elongata are distinguished based on the structure of the copulatory bursa, genital cone, and spicules relative to other ostertagiines, including recently proposed genera such as Africanastrongylus Hoberg, Abrams and Ezenwa, 2008, Hamulonema Hoberg and Abrams, 2008, and Robustostrongylus Hoberg, Abrams and Pilitt, 2009, known in African ungulates. The reduced and shield-like accessory bursal membrane in $P$. elongata (Figs. 17, 18, 23) is most similar to that seen in specimens of H. hamata (Mönnig, 1932), although considerable morphological differences are otherwise evident (Hoberg and Abrams, 2008). Contrary to observations limited to a single male of $P$. elongata summarized in Hoberg et al. (2009a), the reduced dorsal lobe in this species is disposed ventrally rather than dorsally to Rays 8 . Additionally the "ventral genital inflation" described in male specimens (Fig. 15), although similar in position, appears to differ from the proconus (clearly demarcated within the cuticular body wall) known among other ostertagiines, and often best exemplified among some species of Ostertagia (e.g., Hoberg et al., 1993b).

Characteristics of the synlophe for species in 14 of 15 genera among the ostertagiines were recently summarized and compared, although complete information for ridge systems for Pseudomarshallagia were not available (Hoberg et al., 2009b). Parallel systems in the cervical region (Type II lateral and Type A ventral) are typical among species with either a 2-1-2 or 2-2-1 bursal pattern (Lichtenfels et al., 1988). Parallel lateral systems are seen in Cervicaprastrongylus Gibbons and Khalil, 1982, Hamulonema, Hyostrongylus Hall, 1921, some Marshallagia (Orloff, 1933), some Ostertagia Ransom, 1907, Robustostrongylus, and Pseudomarshallagia. Parallel ventral systems, where the ventral-most ridge is bordered by 2 continuous ridges, are observed in Camelostrongylus Orloff, 1933, Hyostrongylus, some Longistrongylus, some Marshallagia, and Ostertagia, Orloffia Dróżdż, 1965, Robusto- strongylus, Sarwaria Dróżdż, 1965, and Pseudomarshallagia. Configuration of the cervical synlophe (either basic tapering or parallel patterns) and bursal structure (either 2-1-2 or 2-2-1) do not appear to be correlated (Hoberg et al., 2009b).

\section{A context for collections}

Correct taxonomy and an understanding of genealogical relationships are fundamental in establishing a foundation to elucidate the structure and history of faunas. This has been demonstrated in studies of trichostrongyline nematodes among ungulates, particularly through recent phylogenetically based approaches exploring the history for species of Haemonchus Cobb, 1898, in Africa and globally (Hoberg et al., 2004). Concurrently, development of museum collections holding archived specimens, with comprehensive geographic and host data, that can be applied to integrated morphological and molecular analyses provide the basis for detailed evaluations of faunal structure, and a range of interrelated issues such as invasive and emergent pathogens (Hoberg, 1997; Brooks and Hoberg, 2000, 2006). For example, knowledge of pathogen biodiversity in source regions from which host animals are translocated provides a baseline against which to assess changing patterns of distribution and dissemination through introductions of hosts and pathogens into new geographic localities (Hoberg, 1997; Smith et al., 2009). These needs, from dual perspectives of curiosity-driven and applied science, establish the rationale for ongoing survey and inventory to elucidate the limits for faunal diversity (Brooks and Hoberg, 2000). Increasingly, the necessity to understand and document distribution, epidemiology, and pathogenic potential for various nematodes in regimes of environmental perturbation further emphasizes the essential nature of intensive and geographically extensive field collections and deposition of representative materials in specimen-based archives (Hoberg, Polley, Jenkins, and Kutz, 2008). Consequently, we strongly encourage routine deposition of voucher specimens from all survey activities designed to explore faunal diversity, or from studies of ecological processes. This is particularly important in regions that remain poorly known such as Africa, but the principle applies more broadly (Hoberg, Pilitt, and Galbreath, 2009). Over time, such activities can serve to build a comprehensive picture for the structure of helminth faunas among free-ranging and domestic ungulates at local, regional, and global scales.

\section{ACKNOWLEDGMENTS}

We gratefully acknowledge Lynda Gibbons and Mark T. Fox at the Royal Veterinary College, London, U.K. for their assistance in providing specimens of various ostertagiine nematodes, including $P$. elongata.

\section{LITERATURE CITED}

Biffa, D., Y. Jobre, And H. ChaKka. 2007. Ovine helminthosis, a major health constraint to productivity of sheep in Ethiopia. Animal Health Research Reviews 7: 107-118.

Brooks, D. R., And E. P. Hoberg. 2000. Triage for the biosphere: The need and rationale for taxonomic inventories and phylogenetic studies of parasites. Comparative Parasitology 68: 1-25.

- AND —. 2006. Systematics and emerging infectious diseases: From management to solution. Journal of Parasitology 92: 426-429.

Dróżdż, J. 1995. Polymorphism in the Ostertagiinae Lopez-Neyra, 1947 and comments on the systematics of these nematodes. Systematic Parasitology 32: 91-99. 
Durette-Desset, M.-C. 1983. Keys to the genera of the superfamily Trichostrongyloidea, Vol. 10. In CIH keys to the nematode parasites of vertebrates, R. C. Anderson and A. G. Chabaud (eds.) Commonwealth Agricultural Bureaux, Farnham Royal, U.K., 86 p.

GibBons, L. M. 1977. Revision of the genera Longistrongylus Leroux, 1931, Kobusinema Ortlepp, 1963, and Bigalkenema Ortlepp, 1963 (Nematoda: Trichostrongylidae). Journal of Helminthology 51: 4162.

. 1981. The taxonomic position of the nematode species Pseudomarshallagia thalae (Troncy and Graber, 1973) Graber and Delavenay, 1978 (Family Trichostrongylidae). Systematic Parasitology 2: $217-218$.

, AND L. F. KHALIL. 1982. A key for the identification of genera of the nematode family Trichostrongylidae Leiper, 1912. Journal of Helminthology 56: 185-233.

Graber, M., and R. Delavenay. 1978. Pseudomarshallagia elongata Roetti, 1941 (Nematoda: Trichostrongylidae), parasite de la caillette des petits ruminants d'Ethiopie. Revue d'Elevage et de Médecine Vétérinaire des Pays Tropicaux 31: 353-359.

Hoberg, E. P. 1997. Parasite biodiversity and emerging pathogens: A role for systematics in limiting impacts on genetic resources. In global genetic resources: Access, ownership and intellectual property rights, K. E. Hoagland and A.Y. Rossman (eds.). Association of Systematics Collections, Washington, D.C., p. 71-83.

—, AND A. Abrams. 2008. Hamulonema gen. nov. for Teladorsagia hamata and Ostertagia kenyensis in the ostertagiine fauna (Nematoda: Trichostrongyloidea) from African ungulates. Journal of Parasitology 94: 866-879.

, AND V. O. EzEnwa. 2008. An exploration of diversity among the Ostertagiinae (Nematoda: Trichostrongyloidea) in ungulates from sub-Saharan Africa with a proposal for a new genus. Journal of Parasitology 94: 230-251.

- AND P. A. Pilitt. 2009a. Robustostrongylus aferensis gen. nov. et sp. nov. (Nematoda: Trichostrongyloidea) in kob (Kobus kob) and hartebeest (Alcelaphus buselaphus jacksoni) from sub-Saharan Africa, with further ruminations on the Ostertagiinae. Journal of Parasitology 95: 702-717.

, — AND — 2009b. Synlophe structure for species of Longistrongylus (Nematoda: Trichostrongyloidea), abomasal parasites among ungulates from sub-Saharan Africa, with comparisons to the global ostertagiine fauna. Journal of Parasitology 95: 1468-1478.

, J. R. Lichtenfels, and L. M. Gibbons. 2004. Phylogeny for species of Haemonchus (Nematoda: Trichostrongyloidea): Considerations of their evolutionary history and global biogeography among Camelidae and Pecora (Arrtiodactyla). Journal of Parasitology 90: 1085-1102. (Trichostrongylidae: Cooperiinae) with comments on vulval inflations and hypertrophy of cuticular ridges among the trichostrongylids. Journal of the Helminthological Society of Washington 60: 153161. Ostertagia mossi and Ostertagia dikmansi (Trichostrongylidae) from Odocoileus virginianus and comments on other Ostertagia spp. from the Cervidae. Systematic Parasitology 24: 111-127.

- K. J. Monsen, S. J. Kutz, and M. S. Blouin. 1999. Structure, biodiversity, and historical biogeography of nematode faunas in Holarctic ruminants: Morphological and molecular diagnoses for Teladorsagia boreoarcticus $\mathrm{n}$. sp. (Nematoda: Ostertagiinae) a dimorphic cryptic species in muskoxen. Journal of Parasitology 85: 910-934.

, P. A. Pilitt, and K. E. Galbreath. 2009. Why museums matter: A tale of pinworms (Oxyuroidea: Heteroxynematidae) among pikas (Ochotona princeps and O. collaris) in the American West. Journal of Parasitology 95: 490-501.

- L. Polley, E. J. Jenkins, and S. J. Kutz. 2008. Pathogens of domestic and free-ranging ungulates: Global climate change in temperate to boreal latitudes across North America. Revue Scientifique et Technique Office International des Épizooties 27: 511-528.

Kumsa, B., And A. Wossene. 2006. Abomasal nematodes of small ruminants of Ogaden region, eastern Ethiopia: Prevalence, worm burden and species composition. Revue Médecine Véterinaire 157: $27-32$.

Lichtenfels, J. R., P. A. Pilitt, And L. M. Gibbons. 2003. Ovejector structure in the Haemonchinae (Nematoda: Trichostrongyloidea) of ruminants. Journal of Parasitology 89: 984-993.

, AND M. B. LANCASTER. 1988. Cuticular ridge patterns of seven species of Ostertagiinae (Nematoda) parasitic in domestic ruminants. Proceedings of the Helminthological Society of Washington 55: 77-86.

RoetTI, C. 1941. Un eliminta del genere parassita degli ovini e capriniNuova specie. Annali di Patologia Tropicale e Parassitologia 2: 251256.

Smith, K. F., M. Behrens, L. M. Schloegel, N. Marano, S. Burgiel, AND P. DASZAK. 2009. Reducing the risks of the wildlife trade. Science 324: 594-595.

Tembely, S., A. Lahlou-Kassi, J. E. O. Rege, S. Sovani, M. L. Diedhiou, AND R. L. BAKER. 1997. The epidemiology of nematode infections in sheep in a cool tropical environment. Veterinary Parasitology 70: 129-141.

Wilson, D. E., And D. M. Reeder. 2005. Mammals species of the world: A taxonomic and geographic reference. Vol. 1. Johns Hopkins University Press, Baltimore, Maryland, 743 p. 